\section{International Scientific Journal Theoretical \& Applied Science}

p-ISSN: 2308-4944 (print) $\quad$ e-ISSN: 2409-0085 (online)

Year: 2015 Issue: 07 Volume: 27

Published: $30.07 .2015 \quad \underline{\text { http://T-Science.org }}$

SECTION 6. Metallurgy and energy.
Arman Arstangalievich Kabdushev

Master of oil and gas

Senior lecturer of the Department of «Oil and gas

engineering»

M.Kh. Dulaty Taraz State University, Kazakhstan

Arman-kz@mail.ru

Aizhan Zharylkasynovna Betzhanova Master of oil and gas

Senior lecturer of the Department of «Oil and gas engineering»

M.Kh. Dulaty Taraz State University, Kazakhstan

\title{
THE PROBLEMS OF INCREASING RESERVOIR PRODUCTIVITY AT THE FIELD AMANGELDY
}

\author{
Abstract: The article discusses the results of the event to increase gas recovery and hydraulic fracturing. \\ Key words: the Amangeldy field, wasootch, hydraulic fracturing, radial drilling, development. \\ Language: Russian \\ Citation: Kabdushev AA, Betzhanova AZ (2015) THE PROBLEMS OF INCREASING RESERVOIR \\ PRODUCTIVITY AT THE FIELD AMANGELDY. ISJ Theoretical \& Applied Science 07 (27): 163-165. \\ Soi: http://s-o-i.org/1.1/TAS-07-27-28 Doi: crossef http://dx.doi.org/10.15863/TAS.2015.07.27.28
}

\section{ПРОБЛЕМЫ ПОВЫШЕНИЯ ПРОДУКТИВНОСТИ ПЛАСТОВ НА МЕСТОРОЖДЕНИИ АМАНГЕЛЬДЫ}

Аннотация: В статье рассматривается результаты проведенных мероприятий по повышению газоотдачи и гидравлического разрыва пласта.

Ключевые слова: месторождение Амангельды, газоотдача, гидравлический разрыв пласта, радиальное бурение, разработка.

Месторождение Амангельды открыто в 1975 году бурением глубокой поисковой скважины 1. Всего на месторождении пробурено 9 поисковых и 6 разведочных скважин. В результате бурения и испытания установлены серпуховский, нижневизейский и турнейский газовые горизонты.

Месторождение

Амангельды характеризуется очень сложным строением пород-коллекторов с невыдержанными по площади и разрезу коллекторскими свойствами пластов, с различными физико-химическими свойствами и составом газа и гидродинамическими характеристиками (пластовыми давлениями), что обуславливает необходимость определенного подхода к выделению объектов эксплуатации, основанном на анализе геолого-геофизической характеристики продуктивных пластов и горизонтов и учета технических и технологических возможностей их разработки.

За период разработки на нижневизейском горизонте месторождения Амангельды проводились мероприятия по повышению газоотдачи, такие как:

- бурение радиальных стволов;
- бурение боковых стволов;

- эксплуатация открытым стволом и с щелевым фильтром;

- гидроразрыв пласта (ГРП).

В Авторском надзоре за 2004 год для повышения продуктивности скважин месторождения Амангельды основным из методов предлагалось бурение боковых стволов и испытание новой технологии - радиального бурения. Указанные рекомендации предлагалось осуществить, в первую очередь, в низкодебитных скважинах 105, 106, 111. По результатам проведенных работ планировалось принимать решения в отношении остальных скважин [1].

В 2005 году в скважине 106 пробурен боковой ствол, позволивший увеличить средний дебит газа скважины с 8.7 тыс.м³/сут (май 2005 г.) до 25,7 тыс.м ${ }^{3} /$ сут (октябрь 2005 г.). Средний дебит газа скважины 106 на 01.07 .2007 г. составил 17,5 тыс.м ${ }^{3} /$ сут, что свидетельствует о положительных результатах выполненных работ по бурению бокового ствола в данной скважине и необходимости реализации этого мероприятия в других скважинах [2].

На основании рекомендаций Авторских надзоров за реализацией Проекта ОПЭ и, исходя 
из опыта бурения бокового ствола в скважине 106 , с целью изучения возможности увеличения дебита скважин, в 2007 году рекомендуется выполнить бурение бокового ствола в скважине 115 с азимутом 360 градусов и отклонением до 500 м. Рекомендуемое направление и отклонение бокового ствола позволит вскрыть продуктивный горизонт в зоне аномалии с улучшенными коллекторскими свойствами, выделенной по сейсмике 2Д.

В период 2006-2007 гг. согласно рекомендациям в трех скважинах 105, 110 и 111 пробурены по 4 радиальных ствола. В результате выполненных работ по радиальному бурению в скважинах 105 и 111 отмечается незначительное увеличение дебита газа в среднем на 2,0 тыс.м ${ }^{3} /$ сут. В скважине 110 дебит газа снизился на 0,88 тыс.м ${ }^{3} /$ сут.

Продолжается проведение испытаний продуктивных пластов в скважинах с открытым стволом и со спуском щелевого фильтра. Эксплуатация скважин таким способом показала свою эффективность. В настоящее время 4 скважины $(102,104,117,121)$ эксплуатируются открытым стволом и 7 скважин $(106,108,114$, $118,119,120,122)$ - со спуском щелевого фильтра [3]. На дату анализа (по состоянию на 01.01.2011 г.) продолжается промышленная разработка газоконденсатной залежи нижневизейского продуктивного горизонта месторождения Амангельды, начавшаяся в декабре 2007 года.

В новых скважинах рекомендуется предусмотреть эксплуатацию с открытым стволом и со спуском щелевого фильтра.

В целях интенсификации добычи газа в сентябре 2007 г. на скважине 110 был проведён гидроразрыв пласта (ГРП) в интервале 2238-2290 м. До проведения ГРП скважина работала с дебитом газа 9,7 тыс.м ${ }^{3} /$ сут и конденсата 0,5 т/сут, после ГРП средний дебит газа по состоянию на 23.10.2007 г. составил 53,2 тыс. м $^{3}$ суут, конденсата 4,9 т/сут.

Гидравлический разрыв пласта (ГРП) представляет собой одну из сложнейших операций в нефтегазодобывающей промышленности. Эта методика уже около 50 лет применяется во всём мире с целью увеличения продуктивности скважин.. Жидкость закачивается в скважину под таким давлениями с таким расходом, которые достаточны для того, чтобы разорвать породу и создать по обе стороны ствола две направленные в противоположные стороны трещины протяженностью до 300 м и более.. Для удержания трещины в раскрытом состоянии при прекращении закачки и снижении давления она набивается переносимыми рабочей жидкостью частицами песка или керамики (называемыми проппантом). Гидроразрыв пласта применяется главным образом к низкопроницаемым (0..1-10мД) породам с целью получения узких, глубоко проникающих в коллектор, проводящих поток жидкости, трещин. Эти линейные каналы, в меньшей степени препятствующие потоку, заменяют радиальные режимы притока и несколько раз повышают дебит.

В 2007 г. компанией «Trican Well Service Kazakhstan Limited» с целью интенсификации добычи газа в 6 скважинах $(101,105,110,116$, $118,120)$ нижневизейского горизонта газоконденсатного месторождения Амангельды были выполнены работы по гидроразрыву. Во всех скважинах работы по ГРП выполнены в период эксплуатации. Гидроразрыв пласта проводился с применением геля со сшивателем на нефтяной основе в количестве около $300 \mathrm{~m}^{3}$ на одну скважину, в т.ч. $150 \mathrm{~m}^{3}$ дизтоплива и $150 \mathrm{~m}^{3}$ стабильного конденсата добытого на месторождении Амангельды. В качестве расклинивающего агента использовался керамический проппант Fores ForeProp 20/40 (производства России) в объеме 80 т.

В качестве химических реагентов применялись:

1. НGA-37 (гель);

2. НGA-44 (сшиватель);

3. OGB-10 (Деструктор);

4. Дизельное топливо;

5. Средний дистиллят;

6. ForesForeProp-20/40 (пропант).

В скважинах газоконденсатного месторождения Амангельды работы по гидравлическому разрыву пласта выполнены с соблюдением оптимальной технологии: применялся гель со сшивателем на нефтяной основе, было закачано достаточно большое количество пропанта $(80 \quad \mathrm{~T}), \quad$ закачка производилась при скорости (2.9-3.1 м3/мин). В результате проведенных ГРП кратность увеличения дебита газа составила в среднем от 5 до 30 раз на одну скважину.

Анализ работ по гидравлическому разрыву пласта в скважинах месторождения Амангельды показывает, что успешность проведения ГРП зависит от правильного выбора скважиныкандидата, необходимого количества техники и материалов, используемых для ГРП и соблюдения оптимальной технологии проведения ГРП.

Результаты выполненных работ по ГРП в 2007-2008 гг. в скважинах газоконденсатного месторождения Амангельды подтверждают, что дебит отдельных скважин можно в значительной степени увеличить за счет проведения гидроразрыва пласта.

Работы по проведению ГРП рекомендуется продолжить. 


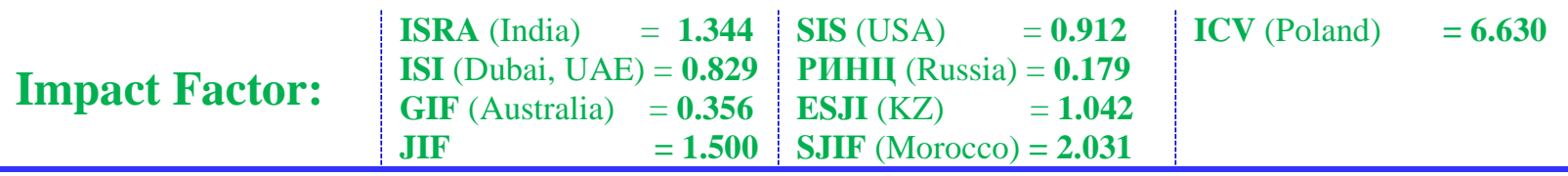

\section{References:}

1. Mambetov UM, Filip'ev GP, Kopkina LN, Shakhabaev RS, et al. (1981) Otchet po podschetu zapasov prirodnykh gazov mestorozhdeniy Amangel'dy i Ayrakty v Muyunkumskoy vpadine Chu-Sarysuyskoy depressii (Dzhambul'skoy oblasti Kazakhskoy SSR) po rabotam za 1971-1981. Chimkent: YuzhKazNRE, 1981.

2. Dake LP (2009) Fundamentals of Reservoir Engineering.

3. (1989) Sputnik petroleum geologist. Handbook ed. by I. P. Cholovskogo. Moscow, Nedra.

4. (2001) Technical manual for geophysical research and work on the cable in oil and gas wells. Moscow, GERS, 2001.

5. F. Jerry Lucia (2007) Carbonate Reservoir Characterization: An Integrated Approach.

6. Gershtanskiy OS, Apakaev ZA, Chagay VG, Pupisova LV, et al. (2007) Avtorskiy nadzor za realizatsiey proekta opytno-promyshlennoy ekspluatatsii mestorozhdeniya Amangel'dy po sostoyaniyu na 01.01.2007. Otchet po dogovoru № 06-MK-048. - Aktau: AO «NIPIneftegaz», 2007.

7. (2004) Supervision of the implementation of the project of experimental-industrial operation of the Amangeldy field as of 01.01.2004.

8. Norman Dzh. Khayn (2008) Geologiya, razvedka, burenie i dobycha nefti, 2008.

9. Korotaev YP, Zakirov SN (1981) The theory and development of gas and gas condensate fields. Moscow, Nedra, 1981.

10. (2009) Otchet «Rezul'taty termodinamicheskogo issledovaniya plastovoy smesi mestorozhdeniya Amangel'dy, skvazhina 116, interval perforatsii: 2118-2128; 21322140; 2145-2148; 2152-2181 m». - Atyrau: TOO «KazNIGRI» 10.07.2009. 